\title{
A EDUCAÇÃO INTERCULTURAL E A HUMANIZAÇÃO EM FREIRE: CONSIDERAÇÕES E CONGRUÊNCIAS
}

\author{
MÁrCIA MARIA RODRIGUES UCHÔA \\ ANGÉLICA SANTOS RAMACCIOTTI \\ Pontifícia Universidade Católica de São Paulo (PUCSP), São Paulo, Brasil
}

Resumo: A finalidade deste artigo é iniciar uma discussão entre a Educação Intercultural, materializada no currículo, e a Humanização em Paulo Freire, destacando as características e as convergências entre ambas, reverberando na elaboração de uma ética educacional para a alteridade. A pesquisa é qualitativa, pautada pelas teorias de Freire $(1980,1982,1987,1989,1997,2006)$, Dussel (2002), Santos $(2010,2011)$, dentre outros. O currículo é visto numa perspectiva de interculturalidade, isto é, que reconhece e valoriza a pluralidade presente nos espaços contemporâneos e proporciona um diálogo horizontal entre as diversas culturas que permeiam o ambiente escolar. Configura-se então em uma proposta humanizadora, uma vez que reconhece os sujeitos do processo educativo, sobretudo aqueles pertencentes aos grupos subordinados e às culturas outras.

Palavras-chave: Interculturalidade. Currículo. Humanização em Paulo Freire. Alteridade.

\section{INTRODUÇÃO}

Sob uma perspectiva antropológica, cultura corresponde ao complexo que engloba conhecimentos, valores, arte, língua, crenças, além de outros elementos adquiridos pelas mulheres e homens pertencentes a uma determinada sociedade. Cultura é definida pelo antropólogo Darcy Ribeiro (2006, p. 37) como:

[...] a herança social de uma comunidade humana, representada pelo acervo coparticipado de modos padronizados de adaptação à natureza para o provimento da subsistência, de normas e instituições reguladoras das relações sociais e de corpos de saber, de valores e de crenças com que seus membros explicam sua experiência, exprimem sua criatividade artística e motivam para a ação.

Analogamente, Freire (1980) entende que cultura corresponde à contribuição dada por mulheres e homens à natureza, resultante da capacidade criadora e recriadora que eles têm e do esforço por transformar e estabelecer diálogos. Assim, ao passo que os seres humanos produzem a cultura também são por ela formados, levando em 
consideração a historicidade e sociabilidade humanas. Em outras palavras, interferimos e transformamos os elementos da natureza e do mundo ao nosso redor, produzindo cultura por meio de diferentes linguagens e símbolos. Esse movimento constante de criar e transformar cultura é o que nos faz seres humanos. Conforme Freire (1989, p. 42):

\begin{abstract}
Todos os Povos têm cultura, porque trabalham, porque transformam o mundo e, ao transformá-lo, se transformam. A dança do Povo é cultura. A música do Povo é cultura, como cultura é também a forma como o Povo cultiva a terra. Cultura é também a maneira que o Povo tem de andar, de sorrir, de falar, de cantar, enquanto trabalha.
\end{abstract}

A educação, compreendida como processo de transmissão da cultura, se concretiza e se transforma em prática por meio do currículo. Desse modo, uma educação compromissada com a transformação do ser humano e do seu entorno deve apresentar um currículo que reconheça a pluralidade dos contextos contemporâneos, respeite os diferentes sujeitos do processo e proporcione um diálogo entre a diversidade de culturas.

A Educação Intercultural, ao reconhecer o valor positivo das diferenças, visibilizar as diversas culturas que permeiam o ambiente escolar e estabelecer um intercâmbio cultural entre os educandos, apresenta-se com um caráter humanizador fundamentado na Pedagogia de Paulo Freire, que tem o diálogo entre as/os diferenças/diferentes como o elemento crucial de sua perspectiva educacional.

Para Freire (1980), é por via do diálogo que o ser humano essencializa a sua humanidade, é pela palavra pronunciada e a problematização concernente a esse discurso que os indivíduos transformam suas vivências e o mundo. Na concepção freireana, é importante ressaltar que diálogo tem intencionalidade, portanto, não é sinônimo de conversa ou bate-papo, tampouco representa um método. Para o autor:

\footnotetext{
O diálogo é uma exigência existencial. E, se ele é o encontro em que se solidariza o refletir e o agir de seus sujeitos endereçados ao mundo a ser transformado e humanizado, não podendo reduzir-se a um ato de depositar ideias de um sujeito no outro, nem tampouco tornar-se simples troca de ideias a serem consumidas pelos permutantes (FREIRE, 1987, p. 45).
}

Assim, temos como objetivo, neste artigo, caracterizar a Educação Intercultural e a Humanização em Paulo Freire, bem como apresentar as congruências entre ambas, tendo em vista uma formação humana direcionada para o reconhecimento da alteridade, para o exercício da empatia, da solidariedade e da justiça social. Além desta introdução, o texto está composto por mais quatro seções que se seguem e se complementam. 
UCHÔA, M. M. R.; RAMACCIOTTI, A. S.

\section{A EDUCAÇÃO INTERCULTURAL: UMA EDUCAÇÃO OUTRA}

Na contemporaneidade, os espaços sociais, sobretudo, os educacionais estão marcados pelo hibridismo e pluralidade cultural, resultantes do processo de globalização que impulsionou o deslocamento dos sujeitos com suas identidades culturais.

Diante das características dos contextos plurais, torna-se premente uma educação pautada no diálogo entre as diferenças e a diversidade, e no exercício da empatia a partir do respeito ao outro. Acerca dessa realidade, Moreira (2011, p. 84-85) enfoca:

[...] quer rejeitemos ou aceitemos a diferença, quer pretendamos incorporá-la à cultura hegemônica, quer defendamos a preservação de seus aspectos originais, quer procuremos desafiar as relações de poder que a organizam, não podemos, em hipótese alguma, negála. Ela está presente em todos os cenários sociais, empobrecendo-os e contaminando-os, segundo alguns, enriquecendo-os e renovando-os, segundo outro. Em síntese, queiramos ou não, vivemos num mundo inescapavelmente multicultural.

Uma perspectiva intercultural na educação, além de confirmar o multiculturalismo que permeia os espaços sociais, promove práticas de reconhecimento do outro pelo diálogo entre os diferentes e sem a hierarquização de grupos culturais. Também entende que as culturas são incompletas, mas podem ser enriquecidas pelo diálogo entre/intercultural, pelas trocas recíprocas de saberes.

A interculturalidade, em conformidade com Catherine Walsh (2019, p. 9), representa:

\footnotetext{
processos de construção de um conhecimento outro, de uma prática política outra, de um poder social (e estatal) outro e de uma sociedade outra; uma outra forma de pensamento relacionada com e contra a modernidade/colonialidade, e um paradigma outro, que é pensado por meio da práxis política.
}

Ou seja, constitui-se em uma educação outra, que questiona e problematiza as práticas de hierarquização cultural, decorrentes do processo de colonização, que são marcadas pelos preconceito e discriminação de grupos culturais, como, por exemplo, indígenas, negros, imigrantes e outros grupos subordinados.

Ainda de acordo com a professora equatoriana, a interculturalidade possibilita pensar a partir da diferença e através da descolonização e da construção de uma sociedade radicalmente distinta. E acrescenta:

[Interculturalidade] é um bom exemplo do potencial epistêmico de uma epistemologia fronteiriça. Uma epistemologia que trabalha no limite do conhecimento indígena subordinado pela colonialidade do poder, marginalizado pela diferença colonial e pelo conhecimento ocidental transferido para a perspectiva indígena do 
conhecimento e de sua concepção política e ética (WALSH, 2002a, p. 27-28 apudWALSH, 2019, p. 29).

De acordo com Tubino (2016), a Educação Intercultural surge na América Latina vinculada à educação bilíngue dos povos indígenas, por essa razão, encontra-se permeada por um viés linguístico e indigenista, tendo como maior desafio na atualidade a superação dos "estigmas tribais".

Para o autor peruano, a desconstrução dos estigmas é imprescindível para se estabelecer uma relação de empatia com o outro, assim:

[...] o diálogo intercultural implica em reconhecer sem pré-julgar, as diversas concepções de mundo e hierarquias de valores que estão em jogo. Dessa forma, implica em reconhecer as diversas sensibilidades e espiritualidades, que pessoas, de diferentes horizontes culturais, possuem. [...] Esse é o ponto de partida (TUBINO, 2016, p. 30).

Analogamente, a Educação Intercultural surge na legislação brasileira também vinculada à educação dos povos indígenas. A Lei de Diretrizes e Bases da Educação Nacional (LDBEN) n. ${ }^{\circ}$ 9394/1996 explicita essa realidade nos artigos 78 e 79, a saber:

Art. 78. O Sistema de Ensino da União, com a colaboração das agências federais de fomento à cultura e de assistência aos índios, desenvolverá programas integrados de ensino e pesquisa, para oferta de educação escolar bilíngue e intercultural aos povos indígenas, com os seguintes objetivos [...].

Art. 79. A União apoiará técnica e financeiramente os sistemas de ensino no provimento da educação intercultural às comunidades indígenas, desenvolvendo programas integrados de ensino e pesquisa (BRASIL, 2017, p. 49-50, grifos nossos).

A ideia da Interculturalidade, voltada à educação bilíngue dos povos indígenas, amplia-se em nosso país a partir de 2005, quando se iniciam as primeiras discussões acerca do Projeto Escola Intercultural Bilíngue de Fronteira (PEIBF), "política pública para a construção de um programa educacional para as escolas das regiões de fronteira, que fazem parte do sistema de cidades-gêmeas internacionais definido pelo Ministério da Integração Nacional" (UCHÔA, 2019a, p. 70). Tal projeto "nasceu da necessidade de estreitar laços de interculturalidade entre as cidades vizinhas de países que fazem fronteira com o Brasil" (BRASIL, 2008b, p. 3). Ou seja, a Interculturalidade é apresentada como princípio do projeto, pelo estabelecimento de diálogo entre os países do Mercosul.

De acordo com Sagaz (2013, p. 41), “o projeto visou promover as línguas espanhola e portuguesa através de uma política linguística com foco no ensino bilíngue e nos intercâmbios culturais entre Argentina e Brasil. Posteriormente, a partir de 2008, a parceria foi ampliada aos demais países". 
UCHÔA, M. M. R.; RAMACCIOTTI, A. S.

O PEIBF foi oficialmente instituído em 2012, com a criação do Programa Escolas Interculturais de Fronteira (PEIF), pela Portaria n. ${ }^{\circ}$ 798/2012, pelo Ministro da Educação à época, Aloízio Mercadante. Em conformidade com Uchôa (2019a, p. 73):

O programa se consolida como política pública comprometida com as necessidades dos contextos de fronteira entre o Brasil e os países vizinhos, pois pelo ensino intercultural, não somente a língua do Outro passa a ser valorizada, mas, a cultura, a história e a identidade. A interação das línguas: português e espanhol, avança para interações sociais que não negam, tampouco subordinam as culturas.

A Educação Intercultural preconizada no programa, materializa-se a partir de um currículo numa perspectiva de interculturalidade, que promove o diálogo entre as diversas culturas que permeiam o contexto escolar e se constitui num desafio às práticas de discriminação, como o racismo, a xenofobia, a homofobia etc.

A aprovação da Lei n. ${ }^{\circ}$ 10.639/2003 no Brasil, que trata da obrigatoriedade da temática "História e Cultura Afro-Brasileira", alterada posteriormente pela Lei n. ${ }^{\circ}$ $11.645 / 2008$, "que estabelece as diretrizes e bases da educação nacional, para incluir no currículo oficial da rede de ensino a obrigatoriedade da temática "História e Cultura AfroBrasileira e Indígena" (BRASIL, 2008a), representou um avanço para os estudos culturais na educação, pela visibilidade ao "outro negro" e ao "outro indígena", pelo reconhecimento das suas histórias e contribuições para a formação social e cultural do nosso país.

Embora saibamos que a Lei ainda não foi devidamente implementada nos contextos educacionais, sua aprovação convoca-nos a lutar em prol do reconhecimento e valorização das "Culturas Outras" no currículo escolar. Sobretudo as culturas negras, vitimizadas por quase quatro séculos de escravidão e exploração no nosso país, processos que se traduzem na atualidade com as práticas do racismo e da segregação a que ainda são submetidas as culturas negras.

Gomes (2010, p. 108) destaca que a construção de uma educação antirracista, que respeite a diversidade e pautada na legislação, anteriormente mencionada, possui muitos desafios, dos quais destacamos: "o incremento dos intercâmbios intelectuais Brasil/África", o que reforça a importância do diálogo intercultural.

Santiago, Akkari e Marques (2013) destacam que a perspectiva intercultural favorece o diálogo entre os diferentes e problematiza os discursos que limitam identidades. Dessa maneira, é possível estabelecer um caráter mais democrático na educação, pelo redimensionamento das relações de poder presentes na sociedade.

Ancoradas em Banks e Lynch (1986), as autoras apresentam três objetivos principais da abordagem intercultural:

[...] (1) reconhecer e aceitar o pluralismo cultural como um fato da sociedade; (2) contribuir para o estabelecimento de uma sociedade de igualdade de direitos e equidade; e (3) contribuir para o estabelecimento de relações interétnicas harmoniosas (SANTIAGO; AKKARI; MARQUES, 2013, p. 57). 
A Educação Intercultural revela-se, dessa maneira, como uma proposta possível para potencializar o diálogo, o exercício da empatia e a resolução de conflitos, decorrentes do convívio com a diversidade. Intercultural é a

Em conformidade com Candau (2016, p. 347), o ponto de partida da Educação

\begin{abstract}
afirmação da diferença como riqueza. Promove processos sistemáticos de diálogo entre diversos sujeitos - individuais e coletivos-, saberes e prática na perspectiva da afirmação da justiça social, econômica, cognitiva e cultural -, assim como da construção de relações igualitárias entre grupos socioculturais e da democratização da sociedade, através de políticas que articulam direitos da igualdade e da diferença.
\end{abstract}

A articulação de direitos da igualdade e da diferença, que a autora se reporta, está solidificada em Santos (2010, p. 313) ao enfocar que "temos o direito de ser iguais sempre que a diferença nos inferioza; temos o direito de ser diferentes sempre que a igualdade nos descaracteriza". Nesse sentido, com a orientação deste princípio ético, temos o direito à igualdade e também o direito às diferenças. A igualdade a preponderar é, sobremaneira, a dos direitos essenciais a todos os sujeitos.

Tal articulação, segundo o sociólogo português, visa à superação de práticas de uniformidade cultural, que desencadeou a assimilação linguística de vários povos, durante o processo de colonização, dentre eles, indígenas e imigrantes (SANTOS, 2010). Boaventura de Souza Santos reconhece o desafio de seguir com o imperativo de descolonizar, pois - além de haver quem acredite que o colonialismo é algo do passado - muitos o confundem com outras questões ou buscam justificativas para essas ações. Nas palavras do autor:

\footnotetext{
Descolonizar é um imperativo bem difícil de concretizar. Por um lado, há quem pense que a descolonização já teve lugar e que por isso o colonialismo é um fato do passado. Por outro lado, mesmo admitindo que o colonialismo continua a existir sob outras formas, é sempre possível confundi-lo com outras relações de poder desigual ou justificá-lo em nome de valores ou de exigências prioritárias. Colonialismo é toda relação de opressão assente na inferioridade supostamente natural, racial ou étnico-cultural do oprimido (SANTOS, 2011, p. 142).
}

Entretanto, existem muitas possibilidades de desvelar as manifestações do colonialismo ainda tão presente na sociedade atual. Por meio da educação humanizadora freireana, por exemplo, busca-se a tomada de consciência crítica e faz-se a denúncia para concretizar a transformação que possibilita o anúncio de uma nova realidade mais justa e solidária. O relato, a seguir, ilustra um desses momentos no contexto dos círculos de alfabetização de adultos em São Tomé e Príncipe, sob a coordenação de Freire (1989, p. 41): 
UCHÔA, M. M. R.; RAMACCIOTTI, A. S.

\begin{abstract}
Os colonialistas diziam que somente eles tinham cultura. Diziam que antes da sua chegada à África nós não tínhamos História. Que a nossa História começou com a sua vinda. Estas afirmações são falsas, são mentirosas. Eram afirmações necessárias à prática espoliadora que exerciam sobre nós. Para prolongar ao máximo nossa exploração econômica, eles precisavam tentar a destruição da nossa identidade cultural, negando a nossa cultura, a nossa História.
\end{abstract}

Em conformidade com Uchôa (2019a), as diferenças, além de serem reconhecidas, precisam ser valorizadas nos contextos plurais e concebidas como riquezas ou vantagens, nas práticas de diálogo, da troca e do intercâmbio cultural.

William (2019) define o intercâmbio cultural como trocas entre as culturas sem o estabelecimento da dominação, no qual as culturas não são sobrepostas, tampouco hierarquizadas, mas concebidas de modo equivalente. Sob essa ótica, ao reconhecer o valor positivo das diferenças, é possível desvelar os grupos culturais historicamente subordinados e invisibilizados nas práticas educacionais e pelo diálogo intercultural, promovendo a troca de saberes e aprendizagens, ao tempo em que oportuniza a equidade entre os sujeitos.

\title{
A ALTERIDADE PRESENTE NO CURRÍCULO
}

O currículo, pautado em uma perspectiva de interculturalidade, constitui-se em um contradiscurso e em uma orientação contra-hegemônica que irrompe com a tradição histórica da primazia das culturas branca, europeia e rica, em detrimento das demais culturas. Sob essa ótica, o currículo passa a ser um espaço de diálogo intercultural, em vista da interação e da aprendizagem mútua, ou seja, a alteridade é reconhecida e valorizada.

De acordo com Martins (2018), a alteridade diz respeito à perceptibilidade do outro, daquele que difere de nós e que não é visibilizado pelos diferentes grupos sociais. A alteridade, sendo um princípio ético de corresponsabilidade com a reprodução e o desenvolvimento da vida do outro (DUSSEL, 2002), é fundada no respeito e na consideração, sobretudo, ao outro excluído, que tem a identidade negada e assimilada pela totalidade hegemônica.

Sendo o currículo resultante de um processo de escolhas, considerando que a educação nunca é um processo neutro, quando pautado na alteridade ocorre a humanização, uma vez que o diálogo intercultural comunica e essencializa as relações humanas.

Visibilizar as culturas no currículo, sobretudo as culturas outras (marginalizadas e periféricas historicamente), é uma tarefa desafiadora, uma vez que a escola deve ser transformada em um espaço de "aculturação", que diferente da acepção de padronização, reflete na constituição de um espaço de convivência social, onde os indivíduos possam relacionar-se positivamente com as diferenças e estabelecer um diálogo intercultural, aberto às aprendizagens mútuas (UCHÔA, 2019a).

Acerca do reconhecimento do outro, Torres Santomé $(2013$, p. 68) enfatiza que as instituições educativas são: 


\begin{abstract}
espaços maravilhosos para fomentar a abertura da mente, para aprender a compartilhar e se envolver em projetos de trabalho e de lazer com pessoas que são diferentes; para aprender a se ver como iguais, sem barreiras que dificultam a comunicação. Os partidos políticos, sindicatos, ONGs, junto aos profissionais de planejamento projeto de espaços rurais e urbanos, da arquitetura, enfrentam um desafio importante para imaginar e construir equipamentos que promovam o encontro de pessoas de diversas culturas e tradições; que rompam as barreiras entre povoados e cidades (assim como entre seus bairros), garantindo o seu encontro e diálogo.
\end{abstract}

Somado a isto, o currículo ao reconhecer o outro, contribui para a concretização da justiça curricular, que segundo o teórico é:

\begin{abstract}
o resultado da análise do currículo que é elaborado, colocado em ação, avaliado e investigado levando em consideração o grau em que tudo aquilo que é decidido e feito em sala de aula respeita e atende às necessidades e urgências de todos os grupos sociais; ajuda-Ihe a ver, analisar, compreender e julgar a si próprios como pessoas éticas, solidárias, colaborativas e corresponsáveis por um projeto de intervenção sociopolítica mais amplo destinado a construir um mundo mais humano, justo e democrático (TORRES SANTOMÉ, 2013, p. 9, grifos nossos).
\end{abstract}

A valorização da manifestação da diversidade cultural no currículo revela-se como um projeto humanitário, que caminha para a defesa de direitos essenciais à dignidade humana.

No tocante à perspectiva intercultural no currículo, Uchôa (2019b, p. 95) é enfática em afirmar que:

considera e respeita a alteridade, entende que a identidade não se opõe à diferença, mas se constrói a partir dela. O Outro passa a ser entendido como sujeito diferente, mas não inferior essa diferença passa a ter uma conotação positiva e a ser um elemento de troca e interação.

O currículo passa a ser um instrumento democrático, que promove o empoderamento das culturas subordinadas, uma vez que questiona e se contrapõe às práticas assimilacionistas que predominaram historicamente no contexto educacional (UCHOA, 2019a).

O currículo aberto à interculturalidade, promove a integração dos conhecimentos constitutivos das culturas subordinadas aos conhecimentos científicos consolidados, rompendo com a separação dos saberes, ao passo em que ao trabalhar com os conteúdos das culturas subjugadas, que foram invisibilizadas e negadas historicamente, aponta pistas para a realização da equidade no espaço escolar. Também se reveste em uma fronteira de negociação e intercâmbio cultural, fundada no reconhecimento de uma ética que valoriza a vida humana. 
UCHÔA, M. M. R.; RAMACCIOTTI, A. S.

É necessário destacar, ainda, que o currículo sob essa perspectiva, passa a ser um instrumento vivo e dinâmico, pois parte das experiências reais dos educandos, superando a tradição fixa e engessada de currículo como programa, plano, grade ou tão somente como conteúdos. O currículo passa a ser a cultura vivida.

Freire (2006, p. 18) discorre que "o diálogo tem significação precisamente porque os sujeitos dialógicos não apenas conservam sua identidade, mas a defendem e assim crescem um com o outro" (FREIRE, 2006, p. 118). O autor ainda ressalta que o exercício da tolerância e do respeito, por meio do diálogo, nos ensina conviver com o outro, aprendendo com quem é diferente e respeitando quem é diferente (FREIRE, 1997).

O diálogo entre os diferentes deve existir para o conhecimento, a compreensão e o respeito à alteridade, um diálogo que deve manter as diferenças e não as eliminar. Considerando-se que o direito à diferença deve ser assegurado por se tratar de um imperativo ético.

\section{O PROCESSO DE HUMANIZAÇÃO EM FREIRE}

Ao nos aprofundarmos no estudo da obra do educador pernambucano Paulo Freire que, além de ser patrono da educação brasileira, também é considerado um clássico mundial, observamos que o diálogo tem um papel de destaque em sua teoria do conhecimento. Assim sendo, para sermos coerentes com a sua proposta, precisamos considerar um conjunto de práticas e posturas, conforme Ramacciotti (2010, p. 24):

[...] é possivel afirmar que o diálogo em Freire requer, exige e possibilita: saber escutar; humildade; tolerância; respeito ao conhecimento do educando; amorosidade; confiança; curiosidade epistemológica; criticidade; construção coletiva do conhecimento; emancipação e transformação social.

Segundo a pesquisadora, a perspectiva freireana fundamenta a existência de mulheres e homens a partir da inspiração em concepções que vão do cristianismo ao marxismo, e do hegelianismo à fenomenologia existencial. Portanto, foi inspirado em autores como "Hegel, Merleau-Ponty, Sartre, Marcel, Mounier, Jaspers, Marx, Luckács, Freud" (DUSSEL, 2002, p. 443) e tantos outros que Paulo Freire desenvolveu uma narrativa considerando a realidade das vítimas do Nordeste brasileiro e também da América Latina (DUSSEL, 2002), ampliando sua pedagogia para países africanos, em um primeiro momento, para depois abarcar outros países periféricos e centrais também, por meio de ações teórico-práticas na perspectiva crítico-emancipatória. No dizer de Dussel (2002, p. 443), trata-se de "uma pedagogia planetária" com a proposta do desenvolvimento

de uma consciência ético-crítica. Sua ação educadora tende, então, não só a uma melhoria cognitiva [...] mas à produção de uma consciência ético-crítica que se origina nas próprias vítimas [...] sujeitos históricos privilegiados de sua própria libertação. 
Inspirado nas correntes de pensamento anteriormente descritas, Freire traz a compreensão de mundo como algo inacabado, e de seres humanos como inconclusos, para o campo da educação. Em sua vida e obra, afirma e reafirma que mulheres e homens não nascem prontos, pois vão se fazendo em um processo que busca superar a condição de objetos e exigir o que são por vocação: sujeitos que podem transformar a realidade em que vivem. Em "Ação cultural para a liberdade e outros escritos", Freire (1982, p. 134) tece a seguinte consideração a esse respeito:

\begin{abstract}
Mulheres e homens são seres humanos porque se fizeram historicamente seres de práxis e, assim, se tornaram capazes de, transformando o mundo, dar significado a ele. É que, como seres de práxis e só enquanto tais, ao assumir a situação concreta em que estamos, como condição desafiante, somos capazes de mudar-lhe a significação por meio de nossa ação. Por isto mesmo é que é impossível a práxis verdadeira no vazio antidialético ao qual leva toda dicotomia sujeito-objeto.
\end{abstract}

Nesse sentido, é importante frisar que o processo de humanização em Freire parte da vocação ontológica do ser humano para "ser mais", pela sua consciência e pelo seu reconhecimento como um ser inacabado e inconcluso. Contudo, o autor deixa claro em suas obras, dentre elas, Pedagogia do Oprimido, que o movimento de busca pelo "ser mais" só se justifica quando está dirigido à humanização e que a desumanização é a distorção da vocação do "ser mais" (FREIRE, 1987). Ao retomar a questão, em Pedagogia da Esperança: um reencontro com a Pedagogia do Oprimido, o autor ressalta a importância da historicidade para que não se confunda com a posição fundamentalista:

[...] ao falar do "ser mais" ou da humanização como vocação ontológica do ser humano, não estou caindo em nenhuma posição fundamentalista, de resto, sempre conservadora. Daí que insista também em que esta "vocação", em lugar de ser algo a priori da história e, pelo contrário, algo que se vem constituindo na história. Por outro lado, a briga por ela, os meios de levá-la a cabo, históricos também, além de variar de espaço-tempo a espaço-tempo, demandam, indiscutivelmente, a assunção de uma utopia. A utopia, porém, não seria possível se faltasse a ela o gosto da liberdade, embutido na vocação para a humanização. Se faltasse também a esperança sem a qual não lutamos (FREIRE, 2006, p. 99).

Daí a necessidade da busca por condições dignas para que a educação humanizadora possa se concretizar, superando "situações-limites". Em outras palavras, pode-se dizer que "situações-limites" se referem à formação de um conjunto de contradições que circundam mulheres e homens de tal forma que eles acabam percebendo essas situações como fatalidades, como algo que não possa ser mudado. Consequentemente, tornam-se impotentes e submissos diante de uma realidade opressora que tenta coisificá-los e não conseguem formular perguntas, tampouco buscar respostas para os desafios que precisam enfrentar. É nesse sentido que a 
UCHÔA, M. M. R.; RAMACCIOTTI, A. S.

educação problematizadora possibilita que o indivíduo desenvolva um pensamento que vai se tornando cada vez mais consciente e mais crítico ao desvelar a realidade opressora circundante para que ele possa se movimentar na busca do "ser mais". Entretanto: "Esta busca do ser mais, porém, não pode realizar-se ao isolamento, no individualismo, mas na comunhão, na solidariedade dos existires, daí que seja impossível dar-se nas relações antagônicas entre opressores e oprimidos" (FREIRE, 1987, p. 43).

Ademais, o autor faz críticas contundentes às tentativas de se responsabilizar o indivíduo de forma exclusiva por aquilo que se considera como sucesso ou fracasso. Em oposição a essa concepção determinista, Freire (1987) defende que não somos simples objetos das circunstâncias, nem somos os que tudo podem, independentemente das circunstâncias vividas. Acerca de fatalismo e subjetivismo, Monteiro (2019, p. 54) afirma que:

\footnotetext{
O determinismo conduz ao fatalismo e o subjetivismo, ao individualismo. Tal concepção está presente nas teorias de autoajuda, que pregam a resolução de problemas através da fé e de pensamentos positivos, nos remetendo à simplificação de problemas e à culpabilização individual por questões complexas que envolvem o coletivo.
}

Quando assumimos que o humano é um ser inconcluso que está sujeito a condicionamentos, a educação é concebida como um "que-fazer" permanente, que se faz e refaz na práxis. Em consonância com Monteiro (2019, p. 41), práxis é aqui entendida como a "ação intencional ou atividade transformadora, que vem sendo construída historicamente". A pesquisadora destaca que o conceito de práxis na educação, fundamentado em Freire, relaciona-se ao processo de libertação de seres humanos, que acontece por meio do diálogo, da problematização, da ação/reflexão/ação, sempre com o objetivo de desvelar a realidade opressora para transformá-la, com vistas à justiça social.

Cabe ressaltar aqui que não se trata de "ensinar" ideias libertadoras, mas convidar mulheres e homens para que, a partir das próprias realidades, passem a reconhecer e a desvelar os condicionamentos de forma crítica, construindo a libertação. Pois quando os condicionamentos são superados e, consequentemente, essa realidade muda, ocorre a vivência de um permanente processo de libertação.

\section{A HUMANIZAÇÃO PRESENTE NO CURRÍCULO: CONSIDERAÇÕES FINAIS}

A perspectiva intercultural ganha materialidade na pedagogia freireana, pois o reconhecimento da cultura do educando não é uma estratégia metodológica, e sim, um dos pressupostos fundamentais para que haja coerência com a proposta, que tem raízes na concepção de ser humano inconcluso e inacabado. Concepção que nos permite sermos educáveis, de forma dialógica, crítica e emancipatória.

Candau e Leite (2006) reforçam que a compreensão das peculiaridades da abordagem cultural em Paulo Freire, perpassa a exploração do seu conceito de cultura, concepção antropológica que envolve toda a produção humana, explicitada na introdução deste artigo. 
Enfim, apresentamos uma perspectiva de Educação Intercultural questionadora e problematizadora das práticas de hierarquização cultural que ocorrem como consequência do processo de colonização, marcado por preconceitos e discriminações de grupos culturais considerados subordinados.

Pautado em uma perspectiva de interculturalidade, o currículo apresenta consonância com as ações humanizadoras, fundamentadas em Freire, e representa uma proposta contra-hegemônica que busca o rompimento com a tradição histórica da primazia das culturas branca, europeia e rica, em detrimento das demais culturas.

Embora o Brasil tenha aprovado, em 2003, uma lei que se propôs a incluir conteúdos vinculados à "História e Cultura Afro-Brasileira" como obrigatória no currículo oficial da Rede de Ensino e, em 2008, tenha alterado essa lei, ampliando a temática obrigatória para "História e Cultura Afro-Brasileira e Indígena" nas diretrizes e bases da educação nacional, tais determinações não foram plenamente efetivadas nas práticas curriculares.

Consideramos a necessidade premente de reconhecer a importância do cumprimento dessas determinações que estão previstas em lei, de forma plena, em todos os Sistemas de Ensino brasileiros para que sejam estabelecidas bases sólidas a partir da perspectiva intercultural na educação. Desse modo, será possível desenvolver um caráter mais democrático na educação, voltada à formação humana, que reconhece a alteridade para o exercício da empatia, da solidariedade e da justiça social.

O currículo, pautado pela interculturalidade, representa um instrumento dinâmico que se converge em uma práxis transformadora, possibilitando a libertação dos sujeitos e o empoderamento das culturas subjugadas no contexto escolar. Portanto, o reconhecimento da alteridade, por intermédio da dialogicidade, reverbera na humanização de mulheres e homens que criam e recriam o mundo.

Artigo recebido em: 26/03/2021

Aprovado para publicação em: 29/06/2021

\section{INTERCULTURAL EDUCATION AND HUMANIZATION IN FREIRE: CONSIDERATIONS AND CONGRUENCES}

ABSTRACT: The purpose of this article is to initiate a discussion between Intercultural Education, materialized in the curriculum, and Humanization in Paulo Freire, highlighting the characteristics and the convergences between both, reverberating in the elaboration of an educational ethics for otherness. The research is qualitative, guided by the theories of Freire $(1980,1982,1987,1989$, 1997, 2006), Dussel (2002), Santos $(2010,2011)$, among others. The curriculum in an intercultural perspective, that is, that recognizes and values the plurality present in contemporary spaces and provides a horizontal dialogue between the different cultures that permeate the school environment, is configured in a humanizing proposal, since it recognizes the subjects of the educational process, especially those belonging to subordinate groups and other cultures. 
UCHÔA, M. M. R.; RAMACCIOTTI, A. S.

KEYWORDS: Interculturality. Curriculum. Humanization in Paulo Freire. Alterity.

EDUCACIÓN INTERCULTURAL Y HUMANIZACIÓN EN FREIRE: CONSIDERACIONES Y CONGRUENCIAS

RESUMEN: El propósito de este artículo es iniciar una discusión entre la Educación Intercultural, materializada en el currículo, y la Humanización en Paulo Freire, destacando las características y las convergencias entre ambas, reverberando en la elaboración de una ética educativa para la alteridad. La investigación es cualitativa, basada en las teorías de Freire $(1980,1982,1987,1989$, 1997, 2006), Dussel (2002), Santos (2010, 2011), entre otros. El currículo en una perspectiva intercultural, es decir, que reconoce y valora la pluralidad presente en los espacios contemporáneos y proporciona un diálogo horizontal entre las diferentes culturas que permean el ámbito escolar, se configura en una propuesta humanizadora, ya que reconoce a los sujetos de la educación. el proceso educativo, especialmente los pertenecientes a grupos subordinados y otras culturas.

PALABRAS CLAVE: Interculturalidad. Currículo. Humanización en Paulo Freire. Alteridad.

\section{REFERÊNCIAS}

BRASIL. Lei n. ${ }^{\circ}$ 10.639, de 9 de janeiro de 2003. Altera a Lei no 9.394, de 20 de dezembro de 1996, que estabelece as diretrizes e bases da educação nacional, para incluir no currículo oficial da Rede de Ensino a obrigatoriedade da temática "História e Cultura Afro-Brasileira", e dá outras providências. Disponível em: <http://www.planalto.gov.br/ccivil_03/leis/2003//10.639.htm>. Acesso em: 20 mar. 2021.

BRASIL. Lei n. ${ }^{\circ} 11.645$, de 10 de março de 2008. Altera a Lei no 9.394 , de 20 de dezembro de 1996, modificada pela Lei no 10.639, de 9 de janeiro de 2003, que estabelece as diretrizes e bases da educação nacional, para incluir no currículo oficial da rede de ensino a obrigatoriedade da temática "História e Cultura Afro-Brasileira e Indígena". 2008a. Disponível em: <http://www.planalto.gov.br/ccivil_03/_ato20072010/2008/lei//11645.htm>. Acesso em: 20 mar. 2021.

BRASIL. PEIBF: Modelo de ensino comum em escolas de zona de fronteira, a partir do desenvolvimento de um programa para a educação intercultural, com ênfase no ensino do português e do espanhol. 2008b. Disponível em: <http://portal.mec.gov.br/seb/arquivos/pdf/Escolafronteiras/doc_final.pdf>. Acesso em: 17 out. 2017.

BRASIL. LDB - Lei de Diretrizes e Bases da Educação Nacional. Brasília: Senado Federal, Coordenação de Edições Técnicas, 2017.

CANDAU, V. M. (Org.). Interculturalizar, descolonizar, democratizar: uma educação "outra"? Rio de Janeiro: 7 Letras, 2016.

Inter-Ação, Goiânia, v.46, n. ed.especial, p. 946-961, set. 2021. Disponivel em: <http://dx.doi.org/10.5216/ia.v46ied.especial.68357>. 
CANDAU, V. M.; LEITE, M. S. Diálogos entre diferença e educação. In: CANDAU, V. M. (Org.). Educação intercultural e cotidiano escolar. Rio de Janeiro, 7 Letras, 2006. p. 121-39.

DUSSEL, H. Ética da libertação: na idade da globalização e da exclusão. 2. ed. Petrópolis, RJ: Vozes, 2002.

FREIRE, P. Conscientização: teoria e prática da libertação: uma introdução ao pensamento de Paulo Freire. 3. ed. São Paulo: Moraes, 1980.

FREIRE, P. Ação Cultural para a liberdade e outros escritos. 6. ed. Rio de Janeiro: Paz e Terra, 1982.

FREIRE, P. Pedagogia do oprimido. 17. ed. Rio de Janeiro: Paz e Terra, 1987.

FREIRE, P. A importância do ato de ler em três artigos que se complementam. 23. ed. São Paulo: Cortez, 1989.

FREIRE, P. Professora sim, tia não: cartas a quem ousa ensinar. São Paulo: Olho D’Água, 1997.

FREIRE, P. Pedagogia da esperança: um reencontro com a pedagogia do oprimido, 13. ed. Paz e Terra, 2006.

GOMES, N. L. Diversidade étnico-racial e Educação no contexto brasileiro: algumas reflexões. In: GOMES, N. L. (Org.). Um olhar além das fronteiras: educação e relações raciais. Belo Horizonte: Autêntica, 2010. p. 97-109.

MARTINS, J. S. Fronteira: a degradação do Outro nos confins do humano. 2. ed. São Paulo: Contexto, 2018.

MONTEIRO, A. R. Prática docente inspirada em Paulo Freire: um estudo desenvolvido na disciplina Didática em uma universidade comunitária. Orientadora: Ana Maria Saul. 2019. 104f. Tese (Doutorado em Educação: Currículo) - Programa de Pós-Graduação em Educação: Currículo, PUC-SP, São Paulo, 2019.

MOREIRA, A. F. B. Currículo: políticas e práticas. Campinas: Papirus, 2011.

RAMACCIOTTI, A. S. A prática de diálogo em Paulo Freire na educação on-line, uma pesquisa bibliográfica digital: aproximações. Orientador: Fernando José de Almeida. 2010. 94f. Dissertação (Mestrado em Educação: Currículo) - Programa de Pós-Graduação em Educação: Currículo, PUC-SP, São Paulo, 2010. 
UCHÔA, M. M. R.; RAMACCIOTTI, A. S.

RIBEIRO, D. O povo brasileiro: a formação e o sentido do Brasil. São Paulo: Companhia das Letras, 2006.

SAGAZ, M. R. P. Projeto escolas (interculturais) bilíngues de fronteira: análise de uma ação político linguística. Dissertação (Mestrado). Universidade Federal de Santa Catarina, Centro de Comunicação e Expressão. Programa de Pós-Graduação em Linguística. Florianópolis, 2013.

SANTIAGO, M. C.; AKKARI, A.; MARQUES, L. P. Educação intercultural: desafios e possibilidades. Petrópolis-RJ: Vozes, 2013.

SANTOS, B. S. A gramática do tempo: para uma nova cultura política. 3. ed. São Paulo: Cortez, 2010.

SANTOS, B. S. Portugal: Ensaio contra a autoflagelação. São Paulo, Cortez, 2011.

TORRES SANTOMÉ, J. Currículo Escolar e Justiça Social: o cavalo de Troia da educação. Porto Alegre: Penso, 2013.

TUBINO, F. Porque a formação cidadã é necessária na educação intercultural? In: CANDAU, Vera Maria (Org.). Interculturalizar, descolonizar, democratizar: uma educação "outra"? Rio de Janeiro: 7 Letras, 2016. p. 22-36.

UCHÔA, M. M. R. Currículo Intercultural na Fronteira: um estudo sobre a política e as práticas de currículo na fronteira Brasil/Bolívia do estado de Rondônia. Orientador: Alípio Márcio Dias Casali. 2019a. 163f. Tese (Doutorado em Educação: Currículo) - Programa de Pós-Graduação em Educação: Currículo, PUC-SP, São Paulo, 2019a.

UCHÔA, M. M. R. Currículo na Fronteira Brasil/Bolívia de Rondônia. Revista Culturas e Fronteiras, Volume 1. Edição Especial - Setembro/2019b, Grupo de Estudos Interdisciplinares das Fronteiras Amazônicas - GEIFA /UNIR. Disponível em: http://www.periodicos.unir.br/index.php/index/user. Acesso em: 10 out. 2019.

WALSH, C. Interculturalidade e decolonialidade do poder um pensamento e posicionamento "outro" a partir da diferença colonial. Revista Eletrônica da Faculdade de Direito da Universidade Federal de Pelotas, Pelotas, v. 05, n. 1, jan.-jul., 2019. Disponível em: $<$ https://periodicos.ufpel.edu.br/ojs2/index.php/revistadireito/article/view/15002/10532 $\geq$. Acesso em: 15 mar. 2021.

WILLIAM, R. Apropriação cultural. São Paulo: Pólen, 2019. 
MÁrCIA MarIA Rodrigues UchôA: Doutora em Educação: Currículo pela PUC-SP (2019). Mestra em Ciências da Linguagem pela Universidade Federal de Rondônia UNIR (2010). Especialista em Psicopedagogia e Gestão Escolar pelo Instituto Cuiabano de Educação - ICE (2007). Licenciada em Pedagogia pela UNIR (2003). Realiza pesquisas acerca dos temas: Currículo, Interculturalidade e Fronteiras.

Orcid: http://orcid.org/0000-0003-0939-5646

E-mail:profa.uchoa@smail.com

Angélica Santos Ramacciotti: Doutora e mestra em Educação: Currículo pela Pontifícia Universidade Católica de São Paulo (PUC-SP) e Jornalista pela Universidade Católica de Santos (UniSantos). Integra a Rede Freireana de Pesquisadores, vinculada à Cátedra Paulo Freire da PUC-SP.

Orcid: https://orcid.org/0000-0001-5100-7163

E-mail: lica.ramacciotti@gmail.com

Este periódico utiliza a licença Creative Commons Attribution 3.0, para periódicos de acesso aberto (Open Archives Initiative - OAI). 